\title{
Asociación entre producción de leche y parámetros reproductivos en biotipos Holstein con diferente potencial productivo
}

\section{Association between milk production and reproductive parameters in Holstein biotypes with different production potential}

\author{
Fabián Danilo Reyes Silva., ${ }^{1,3}$, Juan Chávez Cossío², Luis Alfonso Condo Plaza ${ }^{3,4}$, Pablo \\ Roberto Marini ${ }^{3,5}$
}

Recibido: 06-04-2020 / Revisado: 10-05-2020 / Aceptado: 14-06-2020 / Publicado: 03-07-2020

\begin{abstract}
.
DOI: https://doi.org/10.33262/cienciadigital.v4i3.1273

The objective of this study was to determine productive and reproductive parameters and the existing association between them, in two Holstein biotypes with different productive potential. Retrospective records of 1315 fine cows of the Ecuadorian Holstein biotype and 148 records of pure Holstein, of 46 herds located in the province of Cotopaxi - Ecuador, collected in the period 1996 - 2015, were used. The cows were grouped into two categories: Ecuadorian Holstein (HE) and pure Holstein (HP) and were characterized by milk production adjusting to 305 days of breastfeeding in liters (PLA) and reproductive parameters: age at first delivery in days (PPE), birthconception interval in days (IPC) and number of NP deliveries (NP). The data obtained were analyzed by multiple regression, considering the ratio of goodness. No significant differences in PLA, EPP, IPC and NP were found in HE and HP biotypes. According to the production category, the HE biotype had a slight superiority $(6,686.8 \mathrm{~L} /$ lactation in PLA; PPE is away from the 24 to 27 months considered ideal and shows no association with PLA as well as CPI; $12.5 \%$ and $10 \%$ of milk production depend on

${ }^{1}$ Universidad Estatal Amazónica. Puyo, Ecuador. fabianreyess@ yahoo.es

${ }^{2}$ Universidad Nacional Agraria La Molina, Facultad de Zootecnia, Docente del Departamento de Producción

${ }^{3}$ Centro Latinoamericano de Estudios de Problemáticas Lecheras (CLEPL).

${ }^{4}$ Universidad Regional Amazónica IKIAM. Tena, Napo.

${ }^{5}$ CIC-Universidad Nacional de Rosario (UNR). Facultad de Ciencias Veterinarias, Cátedra de Bovinos de Leche; Argentina; pmarini@unr.edu.ar
\end{abstract} Animal. Lima, Perú. 
the number of births and from the fifth delivery, milk production begins to decline. The behavior of the variables studied, can be assumed to other factors that are influencing the fulfillment of parameters and objectives typical of other systems and discusses the need to rethink dairy goals and objectives that allow the sustainability of livestock.

Keywords: Age at first birth, open days, productive life, livestock.

\section{Resumen.}

El objetivo del presente estudio fue determinar parámetros productivos y reproductivos y la asociación existente entre ellos, en dos biotipos Holstein con diferente potencial productivo. Se utilizaron registros retrospectivos de 1.315 vacas multíparas del biotipo Holstein ecuatoriano y 148 registros de Holstein puro, de 46 hatos ubicados en la provincia de Cotopaxi - Ecuador, recolectados en el periodo 1996 - 2015. Las vacas se agruparon en dos categorías: Holstein ecuatorianas (HE) y Holstein puras (HP) y se caracterizaron en función de la producción de leche ajusta a 305 días de lactancia en litros (PLA) y de los parámetros reproductivos: edad al primer parto en días (EPP), intervalo parto-concepción en días (IPC) y número de partos (NP). Los datos obtenidos se analizaron mediante regresión múltiple, considerando el coeficiente de bondad. No se encontró diferencias significativas en PLA, EPP, IPC y NP en los biotipos HE y HP. De acuerdo a la categoría de producción, el biotipo HE presentó una ligera superioridad (6.686,8 L/lactancia en PLA; la EPP está alejada de los 24 a 27 meses consideradas ideal y no muestra asociación con la PLA al igual que el IPC; el 12,5\% y el 10\% de la producción de leche dependen del número de partos y a partir del quinto parto, empieza a decrecer la producción de leche. El comportamiento de las variables estudiadas, se puede asumir a otros factores que están influyendo en el cumplimiento de parámetros y objetivos propios de otros sistemas y pone en discusión la necesidad de repensar metas y objetivos lecheros que permitan la sustentabilidad de las ganaderías.

Palabras claves: Edad al primer parto, días abiertos, vida productiva, ganadería.

\section{Introducción.}

En el mundo, la ganadería de leche es una de las principales actividades económicas, alrededor de 200 millones de familias de Asia, África y América se dedican a producir leche (FAO, 2018). En Ecuador tiene alta relevancia en la estructura económica y social debido a su gran aporte a la generación de empleo e ingresos económicos de aproximadamente 285.000 productores de leche y más de 1’200.000 personas que se dedican a actividades productivas relacionadas a la leche (MAGAP, 2016); producen algo más de cinco millones de litros diarios de leche en sistemas a pastoreo (ESPAC, 2018), de los cuales el 45 por ciento provienen de pequeños productores, el 32 por ciento de medianos y el 23 por ciento de grandes productores (Grijalva, 2016). 
Conseguir una mayor eficiencia biológica y económica de las vacas demanda de una elevada producción de leche por lactancia y de un buen desempeño reproductivo (Marini y Di Masso, 2019) que ha motivado a los ganaderos a utilizar tecnologías y protocolos de crianza efectiva adaptadas a sistemas a pastoreo (Coffey, 2016), los altos niveles de producción de leche va en desmedro de la performance reproductiva, sin embargo Cerón (2008) indica que no es muy precisa, porque altas producciones a veces coinciden con buenos rendimientos reproductivos; en este contexto es necesario profundizar los estudios para determinar comportamientos productivos y reproductivo de las vacas Holstein a nivel local con el propósito de optimizar los recursos existentes y lograr ganaderías sustentables.

Tener la primera cría a edad avanzada disminuye el valor económico de la vaca, reduce el potencial reproductivo (número de crías) y por consiguiente la producción de leche en su vida productiva (Grajales et al., 2006), a esto se suma que la inversión en la cría y recría de las vaquillonas no produce retorno hasta después del parto o venta, por tanto, es imprescindible prestar atención en los primeros meses de vida de la ternera (Pieroni, 2014).

Marini y Di Masso (2019) en un estudio con datos retrospectivos de 260 vacas primíparas de raza Holstein recolectados en el periodo 1992 - 2012 en Argentina, encontraron una correlación positiva y significativa $(\mathrm{r}=0,346 ; \mathrm{P}=0,0002)$ entre producción de leche y edad al primer parto en vacas puras; sin encontrar asociación $(r=0,078 ; \mathrm{P}=0,282)$ en vacas con registro de cría. De igual manera el intervalo parto-concepción, conocido también como días vacíos o días abiertos, es un parámetro sustancial que indica la eficiencia en la detección del estro y la fecundidad de la vaca, es ampliamente utilizado para evaluar la eficiencia reproductiva del hato (González 2001); además correlacionan con el intervalo entre partos, demostrando asociación positiva 0,22 y 0,55 entre la producción y el intervalo entre partos (Zambiachi et al., 1999, citado por Lamoglia, 2013), aunque, Córdova y Pérez (2005) no encontraron asociación entre producción de leche e intervalo parto-concepción.

El objetivo del presente estudio fue determinar el comportamiento de parámetros productivos, reproductivos y la asociación existente entre ellos en dos biotipos Holstein con diferente potencial productivo, en sistemas a pastoreo en la provincia de Cotopaxi, Ecuador.

\section{Metodología.}

El trabajo se desarrolló utilizando registros productivos y reproductivos retrospectivos pertenecientes a los años 1996 - 2015 de 1.464 vacas multíparas de 46 hatos de la provincia de Cotopaxi, bajo el control lechero de la Asociación Holstein Friesian del Ecuador (AHFE). La misma que se encuentra localizada en la región interandina del Ecuador, en el centro del país, en la Zona: 17 M; coordenadas x: 750402.59 m E y: 9896032.29 m S. Calvache (2014) menciona que se encuentra dentro del clima mesotérmico semi-húmedo a húmedo característico de la zona andina, en alturas comprendidas entre 2.000 y 3.050 m.s.n.m., con 
precipitaciones de 500 a $2.000 \mathrm{~mm}$, la temperatura media va de 10 a 20 grados centígrados, humedad de relativa de 65 a 85 por ciento.

La zona de estudio posee un suelo rico en materia orgánica y agua de regadío, propicio para la producción de forraje verde natural y mejorado durante todo el año (CIL, 2015). Se practica el sistema de pastoreo rotativo, con potreros divididos con cercas de alambres de púas, cercas vivas y cercas eléctricas; la alimentación se basa en forraje verde, suplemento balanceado y residuos de cosecha en el momento del ordeño.

Las vacas se agruparon por su biotipo: Holstein ecuatorianas y Holstein puras; las primeras son vacas que han sido inseminadas o montadas con toro puro registrado y están en el proceso de alcanzar la pureza luego de siete generaciones, mientras que las vacas puras sus ancestros fueron puros y se inseminan con semen de toros puros registrados. Los datos de las vacas se caracterizaron en: producción de leche en litros ajustada a 305 días de lactancia (PLA), edad al primer parto en días (EPP), intervalo parto-concepción en días (IPC) y número de partos (NP). Utilizando la metodología de Marini y Oyarzabal (1999) citado por Marini, et al. (2002), los datos de cada biotipo se agruparon en tres categorías por su producción de leche ajustada a 305 días (baja, media y alta). Para la elaboración de la base de datos se utilizó Microsoft Excel y el análisis de datos en el paquete estadístico Infostat.

El efecto del biotipo sobre las variables de estudio se evaluó con un análisis de varianza a un criterio de clasificación y la comparación de medias se realizó con la prueba de Tukey, a excepción del número de partos que fue analizado con Kruskal-Wallis; mismas pruebas se utilizaron para el análisis de las categorías de producción. La asociación entre variables se calculó mediante el coeficiente de correlación lineal producto-momento de Pearson.

\section{Resultados.}

En la Tabla 1, se aprecia ausencia de diferencias estadísticamente significativas en la producción de leche de los biotipos Holstein $(\mathrm{F}=0,13 ; \mathrm{P}=0,7215)$; de igual manera en la edad al primer parto $(\mathrm{F}=3,27 ; \mathrm{P}=0,071)$, similar comportamiento en el intervalo parto-concepción $(\mathrm{F}=0,28 ; \mathrm{P}=0,5954)$ y número de parto $(\mathrm{P}=0,5077)$.

Tabla 1. Parámetros productivos y reproductivos en bovinos Holstein ecuatoriano y Holstein puro en sistemas a pastoreo.

\begin{tabular}{ccccccccc}
\hline \multirow{2}{*}{ Parámetros } & \multicolumn{3}{c}{ Holstein ecuatoriana } & \multicolumn{3}{c}{ Holstein pura } \\
\cline { 2 - 9 } & n & Media & & E.E & n & Media & & E.E \\
\hline PLA (litros) & 1315 & 4996 & a & 18 & 148 & 4939 & a & 54 \\
EPP (días) & 1315 & 957 & a & 4 & 148 & 979 & a & 12 \\
IPC (días) & 591 & 267 & a & 19 & 65 & 235 & a & 27 \\
${ }^{2}$ NP & 1315 & $1(1-10)$ & a & & 148 & $1(1-8)$ & a & \\
\hline
\end{tabular}


EPP: Edad al primer parto en días; PLA: Producción de leche ajustada a 305 días;

IPC: Intervalo parto-concepción en días

${ }^{2}$ Valores: mediana (rango) Prueba de KruskalWallis

n: Número de datos

E.E.: Error estándar

Medias con una letra común no son significativamente diferentes $(\mathrm{P}>0,05)$

Fuente: Elaboración propia.

Las producciones de leche de los biotipos Holstein ecuatoriano y Holstein pura, son superiores a 4.069 litros por lactancia encontrados por Revelo (2018) en la provincia de Pichincha, Ecuador; a los 4.542 y 4.612 litros para Holstein puras y cruce $\mathrm{H}$ x Bw en Pichincha durante el periodo 2007-2014 (Clavijo et al., 2016); a los 4.132 litros encontrados en Nariño, Colombia por Solarte y Zambrano (2012) y a los 4.333 litros reportados por Bueno (2018) en la altura de Cajamarca - Perú. Aunque, inferior a los 6.142 litros reportados por Analuisa (2004) en vacas Holstein de Pichincha - Ecuador en sistemas a pastoreo. De la misma manera a los 6.154 litros publicados por Quijano y Montoya, (2000). Y muy por debajo a los registrados en los Estados Unidos y Canadá con producciones de 11.313 litros a los 305 días y 10.182 litros en sistemas intensivos (Roca, 2012). Las producciones de leche encontradas en el presente estudio, posiblemente se deba a la alta genética de las vacas, a un conjunto de prácticas de manejo integral y a los ecosistemas de la provincia de Cotopaxi apropiados para la disponibilidad permanente de forraje, que ha permitido que las mismas se adapten satisfactoriamente (CIL, 2015).

La edad al primer parto (EPP) de las vacas Holstein ecuatoriano y puro se encuentran por encima de los 22 a 27 meses considerados para sistemas a pastoreo (García y Gens, 1997; Galvis, 2008). Aunque, similares a los 31,5 meses reportados por Ortiz (2008) en la provincia de Pichincha-Ecuador. Por debajo de los 40,1 meses señalados por Freire (2016) en sistemas a pastoreo en la provincia de Chimborazo, a los 35,4 y 31,7 meses para vacas con registro de cría y puras manejadas bajo un sistema de pastoreo en Argentina (Marini et al., 2015), a los 35 meses reportados por Vallone et al. (2016) en sistemas a pastoreo en Argentina y a los 33,1 meses mostrados por Bueno (2018) en un estudio realizado con datos del periodo 19992013 en Lima-Perú. Mostró valores superiores a los 28,1 meses mencionado por Valencia (2009) en un estudio en la hacienda San Marcos en Cuenca- Ecuador y a los 28,9 meses encontrados por Salazar-Carranza et al. (2013) en vacas Holstein puras de hatos de lechería especializada en Costa Rica. Todos los resultados muestran que existe una gran variación de la edad que llegan las vaquillonas a su primer parto, indicando que no es sencillo cumplir con los objetivos impuestos en otros sistemas de producción. Posiblemente, los elevados costos de alimentación y mano de obra que demanda la cría y recría de las vaquillonas podría ser uno de los factores, aunque el otro debería tener una mirada más integral y evaluar el sistemas productivo en el cual se desarrolla para poder realizar los ajustes necesarios para que las vaquillonas alcancen la pubertad, el peso y la función reproductiva llegando al primer 
parto acorde al sistema en el cual se desarrolla y de esta manera contribuir a mejorar la rentabilidad y el bienestar de las vacas.

El promedio del intervalo parto-concepción (IPC) en los dos biotipos fue muy amplio, lejos de los 82 días para obtener un parto al año (Marini y Di Masso, 2019); siendo superior a los 205 y 196 días para vacas Holstein primíparas y multíparas encontrados por Bueno (2018) en el periodo de 1999 - 2013 a 3.350 msnm en Cajamarca - Perú; a los 141 días reportados por Echeverri, et al. (2011); a los 181 días reportados por Ortiz et al. (2009) en un estudio realizado en cuatro establos de la cuenca lechera de Lima con datos del periodo 1994 - 2002 en un sistema intensivo y a los 217, 160, 161 y 154 días para los cuartiles 1, 2, 3 y 4 en base a la edad al primer parto propuestos por Marini y Di Masso (2019) en vacas Holstein con registro de cría. Los días de intervalo parto-concepción que mostró este grupo de vacas posiblemente pueda deberse a una elevada producción de leche que no es posible sostenerse sin que repercuta en la eficiencia reproductiva, además del balance energético negativo, inadecuados niveles de hormonas gonadotropinas, fallas en la detección del estro, factores ambientales y salud de las vacas, que deben ser analizadas en profundidad para superar la dificultad de preñar luego del parto y conseguir un equilibrio entre producción y reproducción de las vacas lecheras para que pueda ser sustentable.

Entre tanto, la longitud de vida productiva expresado en número de partos encontrados en este estudio es inferior a 3,6 partos reportados por Ferris et al. (2012) en vacas Holstein mestizas, y a los 2,6 - 3,3 partos en vacas de alta producción lechera en Estados Unidos y Alemania (Hare, Norman y Wright, 2006; Knaus, 2009; Frana et al., 2014, citado por Marini y Di Masso, 2019). Sin embargo, el biotipo Holstein ecuatoriano tiene más partos (1-10) que las Holstein puras, pero ambas presentan una corta longitud de la vida productiva.

Tabla 2. Producción de leche ajustada a 305 días en biotipos Holstein según categoría de producción.

\begin{tabular}{ccccc}
\hline \multicolumn{5}{c}{ Holstein ecuatoriana } \\
\hline Producción baja & n & Producción media & n & Producción alta \\
\hline $3316 \pm 32$ a & 438 & $4985 \pm 32$ b & 439 & $6687 \pm 32 \mathrm{c}$ \\
\hline \multicolumn{5}{c}{ Holstein puras } \\
\hline Producción baja & $\mathbf{n}$ & Producción media & $\mathbf{n}$ & Producción alta \\
\hline $3214 \pm 95$ a & 49 & $5032 \pm 95 \mathrm{~b}$ & 50 & $6571 \pm 94 \mathrm{c}$ \\
\hline
\end{tabular}

n: Número de datos

Valores de producción: media aritmética \pm error estándar

a,b,c, Valores con diferente letra en las filas difieren significativamente $(\mathrm{P}<0,05)$

Fuente: Elaboración propia. 
En la Tabla 2 se observa que se han encontrado tres categorías de vacas en cada uno de los biotipos estudiados $(\mathrm{P}<0,05)$ en donde las vacas independientemente del biotipo se comportan de manera similar. La categorización de ambos biotipos Holstein en tres niveles de producción permitió comparar el desempeño reproductivo de los tres grupos. Es así que el 33\% de las vacas poseen bajas producciones con un promedio de leche de 10,8 y 10,5 L/día/lactancia, levemente superior al promedio de 10 L/día para la región sierra del Ecuador (ESPAC, 2017); mientras que en la categoría medio y alto se observó producciones individuales que sobrepasan 16 y 21 litros de leche/día, lo cual muestra un elevado nivel de producción en el 66\% de las vacas registradas en la Asociación Holstein Friesian del Ecuador (AHFE), en comparación a otros hatos lecheros del Ecuador con sistemas similares.

No se debe esperar altos niveles de producción en los sistemas a pastoreo, aunque se crea que con mejorar solo la genética eso podría ser posible, la expresión del potencial productivo debe estar acompañada de un control del ambiente que no es posible garantizar en los sistemas a pastoreo. Es importante que los productores busquen dentro de su rodeo vacas que muestren adaptación al ambiente y fitness (Rauw et al., 1998) lo que le permitirá tener la vaca más conveniente para su sistema de producción. Entre tanto, otros países como Argentina los sistemas lecheros tienden a intensificarse, confinando mayor tiempo a sus vacas y equilibrando el consumo de materia seca con el fin de incrementar los litros de leche producidos por vaca (Frossasco et al., 2017). Sin embargo, en la provincia de Cotopaxi y la región interandina, los ecosistemas existentes permiten disponer de forraje verde de buena calidad y cantidad durante todo el año, con ligeros descensos propios de la época de verano (CIL, 2015) apta para el desarrollo de sistemas de producción a pastoreo, en espera de aprovechar al máximo el potencial productivo sin provocar un desequilibrio reproductivosanitario.

Tabla 3. Edad al primer parto (días) de biotipos Holstein según categoría de producción.

\begin{tabular}{cccccc}
\hline \multicolumn{7}{c}{ Holstein ecuatoriana } \\
\hline n & Producción baja & n & Producción media & n & Producción alta \\
\hline 438 & $955 \pm 7$ a & 438 & $961 \pm 7$ a & 439 & $954 \pm 7$ a \\
\hline \multicolumn{7}{c}{ Holstein puras } \\
\hline n & Producción baja & n & Producción media & n & Producción alta \\
\hline 49 & $979 \pm 21$ a & 49 & $962 \pm 21$ a & 50 & $995 \pm 21$ a \\
\hline
\end{tabular}

n: Número de datos

Valores de producción: media aritmética \pm error estándar

a. Medias con una letra común no son significativamente diferentes $(\mathrm{P}>0,05)$

Fuente: Elaboración propia. 
En la Tabla 3 se observa que la edad al primer parto no presenta diferencias estadísticamente significativas $(\mathrm{P}>0,05)$ según las categorías de producción para ambos biotipos Holstein analizados. El biotipo Holstein ecuatoriano presenta los promedios más bajos (31 - 32 meses) de edad al primer parto, demostrando mayor producción de leche con menor EPP, no así las Holstein puras que mostraron un nivel de producción elevado con mayor edad al primer parto. Por consiguiente, en este estudio el nivel de producción de leche tendría relación con la edad al primer parto, siendo indistinto también para los biotipos estudiados. Vitullo, Sarramone y Dick (2016) y por Marini y Di Masso (2019) reportaron similares resultados.

Por el contrario, otros autores indican que los retrasos en la edad al primer parto producen mayor cantidad de leche (Castillo-Badilla et al., 2013; Salazar-Carranza et al., 2013), mientras que Lasa (2015) menciona que los partos entre 18 y 26 meses de edad, provocan un aumento en la producción de leche en la primera lactancia y una disminución, a medida que aumenta la edad al primer parto. Consecuentemente, la edad al primer parto está alejada de los 22 a 27 meses considerados óptimos para sistemas a pastoreo (García y Gens, 1997; Galvis, 2008).

En el mismo sentido la figura 1 muestra la inexistencia de asociación entre la producción de leche ajustada a 305 días y la edad al primer parto de los biotipos Holstein ecuatoriana y Holstein pura $(\mathrm{r}=0,010 ; \mathrm{r}=0,11)$.

Figura 1. Asociación de la producción de leche (L) ajustada a 305 días con la edad al primer parto (días) en dos biotipos Holstein en sistemas a pastoreo.

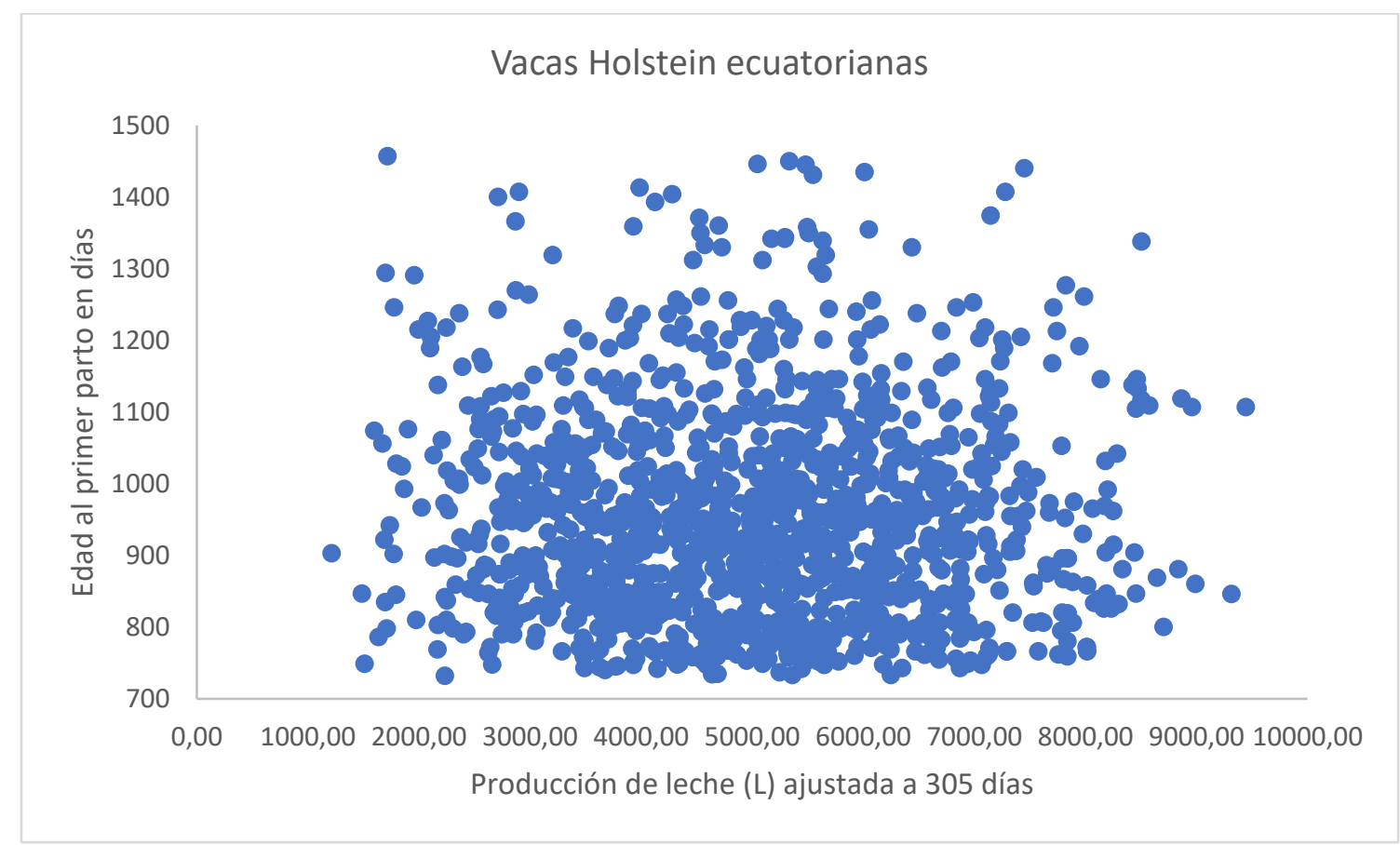




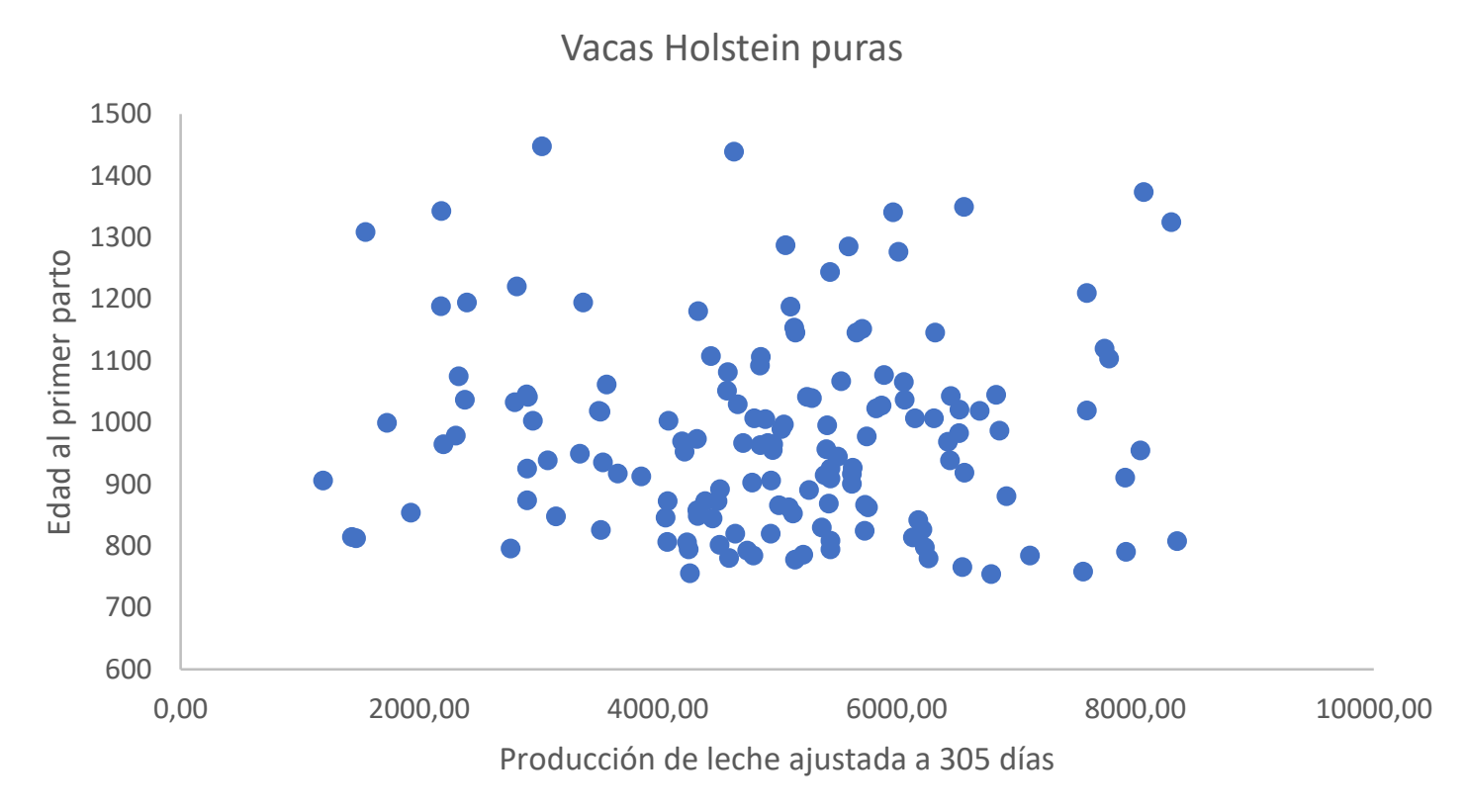

Fuente: Elaboración propia.

Tabla 4. Intervalo parto-concepción (días) de biotipos Holstein según categoría de producción

\begin{tabular}{ccccccc}
\hline \multicolumn{7}{c}{ Holstein ecuatoriana } \\
\hline n & Producción baja & n & Producción media & n & Producción alta \\
133 & $262 \pm 13$ a & 195 & $276 \pm 11$ a & 263 & $249 \pm 9$ a \\
\hline \multicolumn{7}{c}{ Holstein puras } \\
\hline n & Producción baja & n & Producción media & n & Producción alta \\
17 & $271 \pm 17$ a & 17 & $257 \pm 37$ a & 31 & $235 \pm 27$ a \\
\hline
\end{tabular}

n: Número de datos

Valores de producción: media aritmética \pm error estándar

a. Medias con una letra común no son significativamente diferentes $(\mathrm{P}>0,05)$

Fuente: Elaboración propia.

La Tabla 4 muestra los resultados del intervalo parto-concepción sin diferencias estadísticas significativas $(\mathrm{P}>0,05)$ en los dos biotipos Holstein agrupados según la categoría de producción. Lo que se puede interpretar que independientemente del nivel productivo los valores del intervalo parto-concepción están elevados del óptimo de los 82 días considerados para obtener una cría por año, indicando que existen otros factores de relevancia que afectan la eficiencia reproductiva. 
En la Figura 2, se muestra una gran dispersión del valor del intervalo parto-concepción, e indica la no existencia de asociación entre la producción de leche ajustada a 305 días, y el intervalo parto concepción $(r=0,059 ; r=0,18)$.

Figura 2. Asociación de la producción de leche (L) ajustada a 305 días con el intervalo parto concepción (días) en dos biotipos Holstein en sistemas a pastoreo.

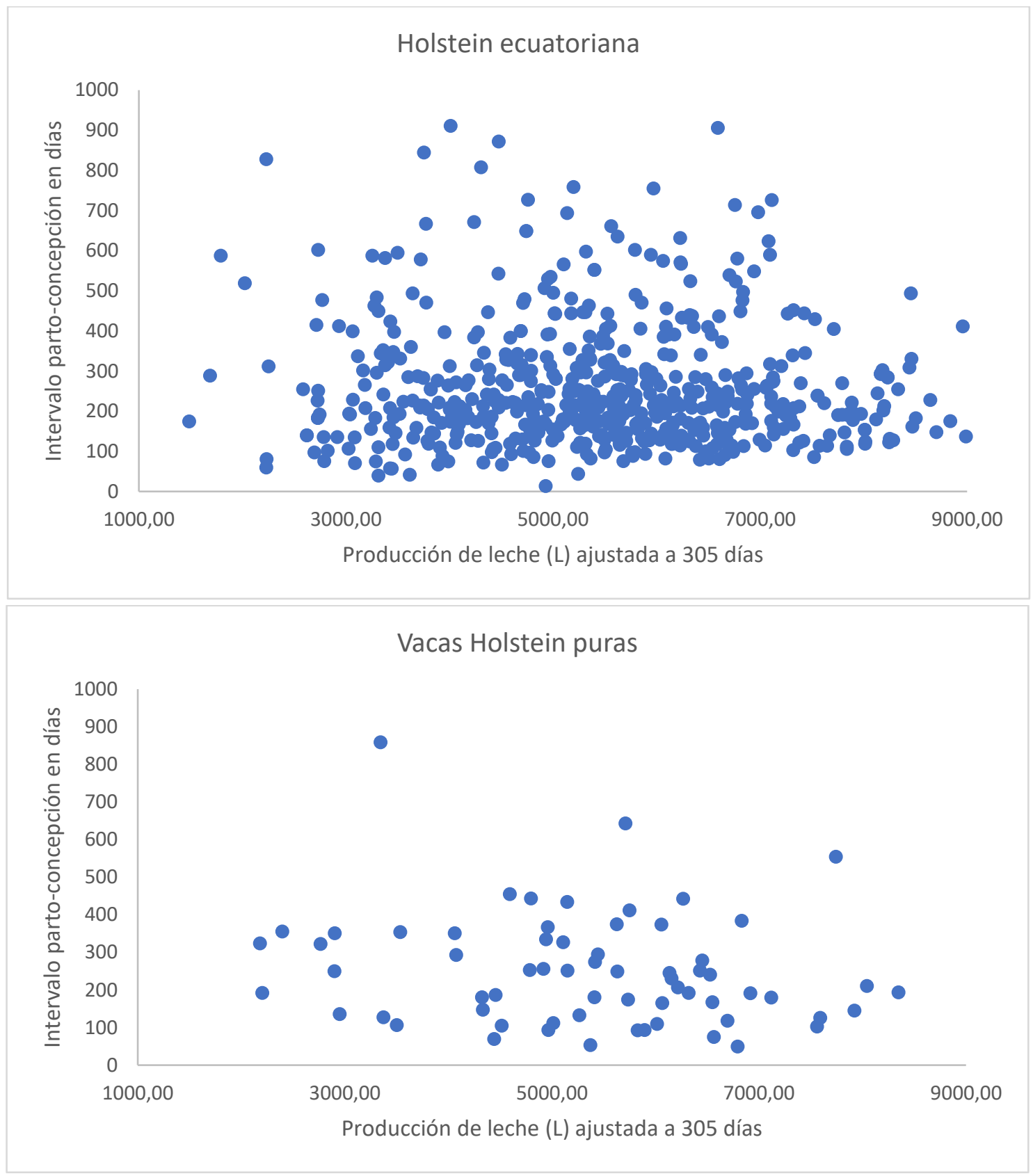

Fuente: Elaboración propia. 
De igual manera, Córdova y Pérez (2005) en un estudio realizado en el establo lechero de Texcoco, México tampoco encontraron asociación entre la producción de leche y el intervalo parto-concepción, reportaron valores de $\mathrm{r}=0,025 ; 0,021 ; 0,026 ; 0,021 ; 0,022$ y 0,056 en los años: 1998, 1999, 2000, 2001,2002 y 2003). Sin embargo, Kim y Suh (2003) y Marini, Charmandarian y Di Masso (2007) señalan que las vacas en su primer parto con niveles elevados de producción de leche, disminuirían su capacidad de reiniciar la actividad reproductiva, de la misma manera Roche et al. (2013) sostienen que las vacas con una alta producción de leche presentan desordenes posparto.

La Tabla 5 muestra la presencia de diferencias significativas $(\mathrm{P}<0,001)$ en el número de partos de los biotipos estudiados agrupados por categoría de producción; las de alta producción en los dos biotipos manifestaron tener mayor vida productiva al igual que el biotipo Holstein ecuatoriana, pone en evidencia la reposición del 33\% en vacas de alta producción.

Tabla 5. Número de partos de biotipos Holstein según categoría de producción

\begin{tabular}{cccccc}
\hline \multicolumn{7}{c}{ Holstein ecuatoriana } \\
\hline $\mathbf{n}$ & Producción baja & $\mathbf{n}$ & Producción media & $\mathbf{n}$ & Producción alta \\
\hline 438 & $1(1-8) \mathrm{a}$ & 438 & $1(1-10) \mathrm{b}$ & 439 & $3(1-9) \mathrm{c}$ \\
\hline \multicolumn{7}{c}{ Holstein puras } \\
\hline $\mathbf{n}$ & Producción baja & $\mathbf{n}$ & Producción media & $\mathbf{n}$ & Producción alta \\
\hline 49 & $1(1-4)$ a & 49 & $1(1-6) \mathrm{b}$ & 50 & $3(1-8) \mathrm{c}$ \\
\hline
\end{tabular}

n: Número de datos

Valores de producción: corresponden a la mediana y rango

a,b,c, Valores con diferente letra en las filas difieren significativamente $(\mathrm{P}<0,05)$

Fuente: Elaboración propia.

Mientras que el valor de la mediana del número de partos en las dos primeras categorías es bajo, sin embargo, considerando el promedio se necesitará un 50\% de reposición anual. Valores que están alejados de los cuatro partos de vida productiva considerados aceptables para una buena rentabilidad.

La figura 3, muestra la representación cuadrática del comportamiento de la producción de leche y el número de partos, resalta la baja asociación en los biotipos Holstein ecuatoriana y Holstein pura, en donde apenas el 12, 5\% y el $10 \%$ de la producción de leche dependen del número de partos a una regresión de segundo orden. De la misma manera se nota que, a partir del quinto parto la producción de leche empieza a decrecer; sin embargo, aquellas vacas que se han mantenido hasta el octavo y décimo parto presentaron moderadas producciones de leche. 
Figura 3. Asociación de la producción de leche (L) ajustada a 305 días con el número de partos en dos biotipos Holstein en sistemas a pastoreo.

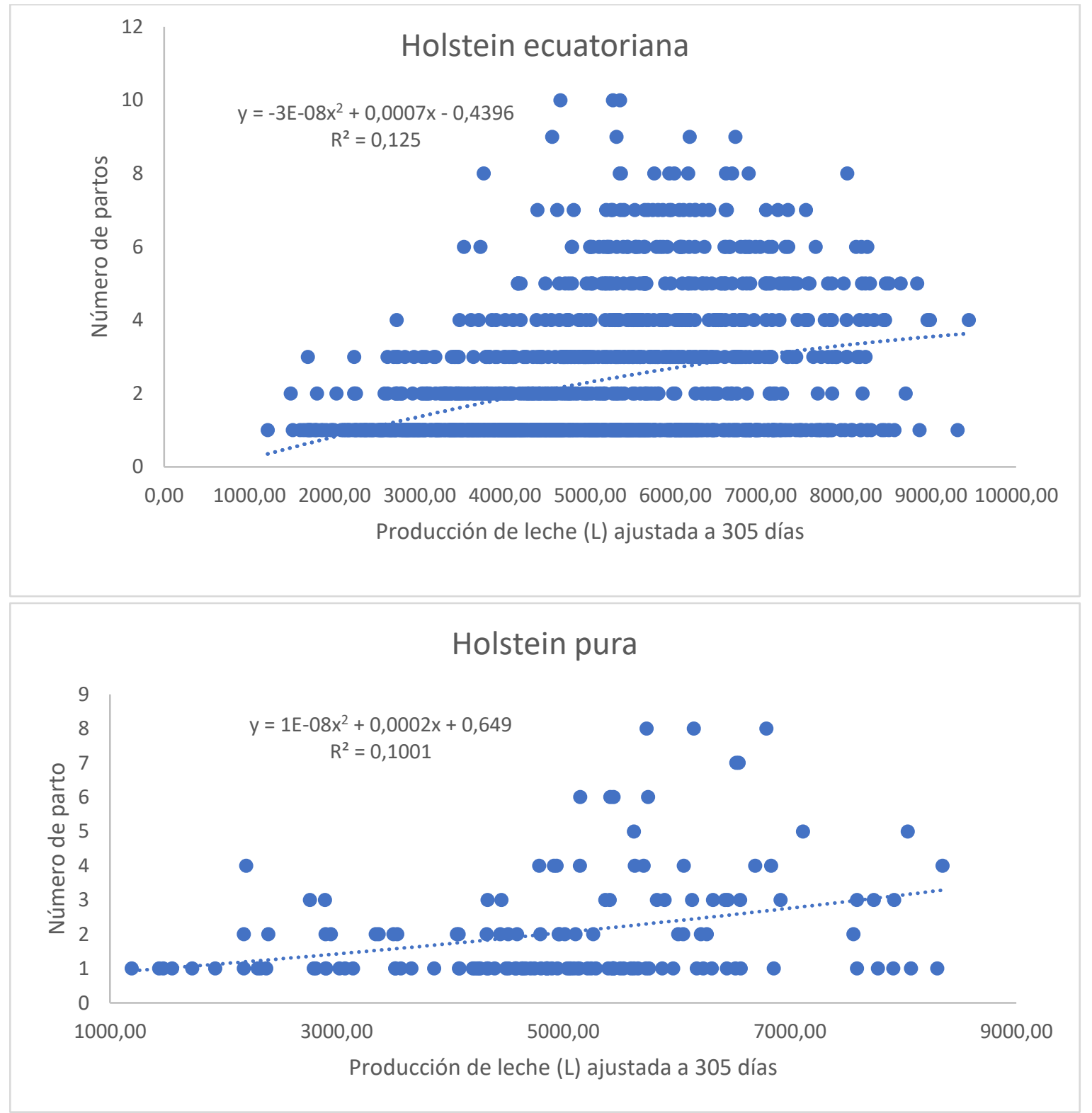

Fuente: Elaboración propia.

Barrera (2017) no encontró diferencias significativas $(\mathrm{P}>0,05)$ entre la producción de leche y el número de parto; sin embargo, Carvajal y Valencia (2002) en vacas Holstein en México, reportaron mayor producción de leche en vacas de tercero, cuarto y quinto parto, de igual manera Linn (1988) sostiene que la mayor producción de leche se alcanza entre el tercero y quinto parto. Gran parte del aumento de producción de leche se debe a que el organismo utiliza los nutrientes consumidos para el mantenimiento y producción, por tanto, el desarrollo corporal produce un aumento del aparato digestivo y la glándula mamaria, mientras que en lactancias a edades tempranas el organismo animal sigue creciendo. 
Los resultados encontrados de PLA, EPP, IPC y NP en sistemas a pastoreo ponen en duda el cumplimiento de parámetros considerados óptimos propios de otros sistemas productivos; la producción de leche es muy susceptible a cambios ambientales temporales; por tanto, se confirma lo mencionado por Marini y Di Masso (2019) que en la producción de leche en sistemas a pastoreo existen factores desconocidos o bien conocidos pero difíciles de controlar en sistemas extensivos, que limitan el cumplimiento de parámetros y objetivos establecidos para sistemas intensivos y en ambientes diferentes.

\section{Conclusiones.}

- Los parámetros productivos y reproductivos estudiados se comportan de similar manera para los biotipos y el sistema estudiado.

- Se pone en discusión el propósito de tener vacas de producción de leche superior que podría ir en desmedro de los parámetros reproductivos, y la necesidad de repensar las metas y objetivos lecheros con animales funcionales y prácticas de manejo acorde a la realidad de la zona y país que permitan la sustentabilidad de las ganaderías.

\section{Referencias bibliográficas.}

Analuisa, I. (2004). Evaluación de la eficiencia productiva y reproductiva de diez hatos lecheros de Aloag, Alausí, Machachi y Tambillo, en la Provincia de Pichincha (Tesis de grado). Escuela Superior Politécnica de Chimborazo, Riobamba, Ecuador.

Barrera, J. (2019). Relación del número de parto y el nivel de producción con las excreciones de nitrógeno de ganado bovino productor de leche (Tesis de maestría). Recuperado de http://ri-ng.uaq.mx/handle/123456789/1407

Bueno, C. (2018). Índices productivos y reproductivos en vacunos Brown Swiss, Jersey y Holstein en altura-Cooperativa Atahualpa Jerusalen, Cajamarca 1999-2013 (Tesis de maestría). Recuperado de http://repositorio.lamolina.edu.pe/handle/ UNALM/3526.

Carvajal-Hernández, M., Valencia-Heredia, E. R., y Segura-Correa, J. C. (2002). Duración de la lactancia y producción de leche de vacas Holstein en el Estado de Yucatán, México. Revista Biomédica. 13(1), 25-31.

Cerón, J.H. (2008). Causas y tratamientos de la infertilidad en la vaca lechera (Tesis de maestría). Universidad Nacional Autónoma de México.

CIL (Centro de la Industria Láctea de Ecuador). (2015). La leche del Ecuador: historia de la lechería ecuatoriana. 15, 192.

Clavijo, F., Rodríguez, I., Luis, F., Yánez, I., Godoy, A., Garzón, J., ... \& Marini, P. (2016). Productive and reproductive evaluation of holsteins and Brown swiss x Holstein in 
Ecuador (en línea). Asian Journal of Agriculture and Food Sciences. 4(4), 219-223.

Recuperado de http://repositorio.iniap.gob.ec/handle/41000/4198

Coffey, E., Horan, B., Evans, R. \& Berry, D. (2016). Milk production and fertility performance of Holstein, Friesian, and Jersey purebred cows and their respective crosses in seasonal-calving commercial farms. J. Dairy Sci. 99(7), 5681-5689. doi:10.3168/jds. 2015-10530

Córdova A. y Pérez, J. (2005). Relación reproducción-producción en vacas Holstein (en línea). REDVET. Revista Electrónica de Veterinaria. 6(2): 1-4. Recuperado de https://www.redalyc.org/pdf/636/63612654014.pdf

Echeverri Z., Salazar R. y Parra S. (2011). Análisis comparativo de los grupos genéticos Holstein, Jersey y algunos de sus cruces en un hato lechero del norte de Antioquia, Colombia. Zootecnia Trop. 29 (1), 49-59.

ESPAC. (2017). Encuesta de Superficie y Producción Agropecuaria Continua. Consultado 25 dic. 2017. Recuperado de https://www.ecuadorencifras. gob.ec/documentos/webinec/Estadisticas_agropecuarias/espac/espac_2017/ Informe Ejecutivo_ESPAC_2017.pdf

ESPAC. (2018). Encuesta de Superficie y Producción Agropecuaria Continua. Consultado 5 ene. 2019. Recuperado de https://www.ecuadorencifras.gob.ec /estadisticasagropecuarias-2/

FAO. (2018) Ganadería sostenible y cambio climático en América Latina y el Caribe. Recuperado de http://www.fao.org/americas/prioridades/ganaderia-sostenible/es/

Ferris, C., Vance, E., Park, R., Hunter, B., Mayne, S., Mackey, D., Kilpatrick, D. \& Watson S. (2012). A comparison of the performance of Holstein-Friesian and Jersey crossbred cows across a range of Northern Ireland milk production systems. The Northern Ireland Agricultural Research and Development Council. AgriSearch. Irlanda. 36.

Freire, M. (2016). Evaluación de parámetros productivos y reproductivos en ganaderías bovinas de la provincia de Chimborazo afiliadas a la Asociación Holstein Friesian del Ecuador (Tesis de grado). Escuela Superior Politécnica de Chimborazo. Riobamba, Ecuador.

Frossasco, G., Garcia F., Odorizzi, A., Ferrer, J., Brunetti, M. y Echeverría A. (2017). Evaluación de distintos sistemas lecheros intensivos. Inf. téc. Área Producción Animal EEA INTA Manfredi. Online: https : //bit.ly/2GvCI2T. 
Galvis, R. (2008). Aspectos fisiológicos del crecimiento con relación a la producción de leche. Universidad Nacional de Colombia, Medellín, 74.

García Bouissou, R. y Gens, M. (1997). Edad al primer parto en vaquillonas Holstein: relaciones con el comportamiento productivo y reproductivo. Memorias del IV Simposio Lechero de Tandil. Ed. Estudio Ganadero Pergamino. Argentina. 33-38.

González, C. (2001). Parámetros, cálculos e índices aplicados en la evaluación de la eficiencia reproductiva. Reproducción Bovina, 203-247.

Grajales, H., Hernández, A. y Prieto, E. (2006). Edad y peso a la pubertad y su relación con la eficiencia reproductiva de grupos raciales bovinos en el trópico colombiano. Livestock Research for Rural Development 18 (139). Recuperado de http://www.lrrd.org/lrrd18/10/graj18139.htm

Grijalva, J. (13 mar. 2016). La Asociación de ganaderos de la sierra y el oriente del Ecuador. Quito, Ecuador. AGSO. Disponible en: http://www.telegrafo.com.ec/ economia/item/produccion-lechera-mue-700-millones-al-ano.html.

Hare, E., Norman, H. y Wright, J. (2006). Trends in calving age and calving intervals for dairy cattle breeds in the United States (en línea). Journal of dairy science 89(1): 365370. Recuperado de https://bit.ly/2BFe5wr.

Hernández-Cerón, J. (2016). Fisiología clínica de la reproducción de bovinos lecheros, $1^{\text {a }}$ ed. Universidad Autónoma de México. 87.

Kim, IH. \& Suh GH. (2003). Effect of the amount of body condition loss from the dry to near calving periods on the subsequent body condition change, occurrence of postpartum diseases, metabolic parameters and reproductive performance in Holstein dairy cows. Theriogenology 60 (8), 1445-1456. Recuperado de https:// bit.ly/2EeeJmf.

Knaus, W. (2009). Dairy cows trapped between performance demands and adaptability. Journal of the Science of Food and Agriculture. 89(7), 1107-1114. Recuperado de https: / / bit. ly / 2BHWtA5.

Lammoglia Villagómez, M.Á., Ávila García, J., Alarcón Zapata, M.A., Cabrera Núñez, A., Gutiérrez Rodríguez, A. \& Daniel Rentería, I. (2013). Rendimientos productivos y reproductivos de vacas lecheras en el primer cruzamiento rotativo en el altiplano del centro de México. Veterinaria México, 44(1), 17-22.

Lasa, D. (2015). Comportamiento productivo y reproductivo de la población de bovinos Holando Argentino en las cuencas lecheras de la República Argentina. (Tesina). Facultad de Ciencias Veterinarias, UNCPBA. 46. 
Linn. (1988). Factors Affecting the Composition of Milk from Dairy Cows. National Academies Press (US). Recuperado de https://www.ncbi.nlm.nih.gov/books/ NBK218193/

MAGAP. (2016). La política agropecuaria ecuatoriana: hacia el desarrollo territorial rural sostenible: 2015-2025. I Parte. Quito, Ecuador. 20.

Marini, P. y Di Masso, R. (2019). Edad al primer parto e indicadores de eficiencia en vacas lecheras con diferente potencialidad productividad en sistemas a pastoreo (en línea). La Granja: Revista de Ciencias de la Vida. 29(1), 84-96. Consultado17 ago.2018. Recuperado de http://doi.org/10.17163/lgr.n29.2019.07.

Marini, P., Castro, R., Frana, E. y Di Masso, R. (2016). Eficiencia biológica de biotipos lecheros de primera lactancia en sistemas a pastoreo. Revista Veterinaria. 26 (2), 136142.

Marini, P., Charmandarian, A. y Di Masso, R. (2007). Desempeño productivo y reproductivo de vacas de diferentes edades al primer parto en sistemas a pastoreo. Sitio Argentino de Producción Animal. APPA-ALPA-, 1-4. Consultado 29 jun. 2018. Recuperado de http: //www.produccionlbibrangedash animal.com. ar/.

Ortiz, D., Camacho, J. y Echevarría, L. (2009b). Parámetros reproductivos del ganado vacuno en la cuenca lechera de Lima. Investigaciones Veterinarias del Perú. 196- 202.

Ortiz, H. (2008). Evaluación reproductiva y productiva del hato lechero Holstein friesian de la Hacienda San Luis durante el periodo 2002 - 2006 (Tesis de grado). Escuela Superior Politécnica de Chimborazo. Riobamba, Ecuador.

Pieroni, G. (2014). Curso Producción Bovinos de Leche. Recría de vaquillonas en el tambo. Inf. téc. 6. Recuperado de https://bit.ly/2SGzgZH: Vetifarma.

Quijano Bernal, J. y Montoya Serna, C. (2000). Comparación productiva de vacas Holstein y f1 blanco orejinero (Bon x Holstein 1). producción y calidad de la leche (en línea). Revista Facultad Nacional de Agronomía Medellín. 15 p. Consultado 2 ene. 2018. Recuperado de https://repositorio.unal.edu.co/bitstream/handle/ unal/36451/24138 84504-1-PB.pdf?sequence=1\&isAllowed=y

Rauw, W. M., Kanis, E., Noordhuizen-Stassen, E. N., \& Grommers, F. J. (1998). Undesirable sideeffects of selection for high production efficiency in farm animals: a review. Livest Prod Sci, 56 (1), 15-33. https://doi.org/10.1016/S0301-6226(98)00147-X

Revelo, L. (2018). Evaluación de parámetros productivos y reproductivos de la cruza bovina Montbeliarde con Holstein en la hacienda El Prado, cantón Rumiñahui, provincia de Pichincha (Tesis de grado). Escuela Superior Politécnica del Ejercito. Quito, Ecuador. 
Roca, A. (2012). Influencia de la raza sobre el rendimiento del ganado vacuno lechero. Centro de Investigaciones Agrarias Mabegondo (CIAM), Coruña. Rev. Albeitar, España, 154 (20).

Roche, J., Kay, J., Friggens, N., Loor, J. y Berry, D. (2013). Assessing and managing body condition score for the prevention of metabolic disease in dairy cows (en línea) Veterinary Clinics: Food Animal Practice 29 (2), 323-336. Consultado 18 ene. 2019. Recuperado de https://bit.ly/2GuI920.

Salazar-Carranza, M., Castillo-Badilla, G., Murillo-Herrera, J., Hueckmann-Voss, F. y Romero-Zúñiga, J. (2013). Edad al primer parto en vacas Holstein de lechería especializada en Costa Rica. Agronomía Mesoamericana. 24(2), 233-243.

Solarte, C. y Zambrano, G. (2012). Characterization and genetic evaluation of Holstein cattle in Nariño, Colombia. Revista Colombiana de Ciencias Pecuarias, ISSN-e 0120-0690. 25 (4), 539-547.

Valencia, F. (2009). Estimación de los Valores Genéticos de la Hacienda San Marcos para la Implementación de un Programa de Inseminación Artificial (Tesis de grado). Escuela Superior Politécnica de Chimborazo. Riobamba, Ecuador.

Vallone, R., Camiletti, E., Exner, M., Mancuso, W. y Marini, P. (2016). Análisis productivo y reproductivo de vacas lecheras Holstein, Pardo Suizo y sus cruzas en un sistema a pastoreo. Revista veterinaria, 25 (1), 40-44.

Vitullo, M., Sarramone, C. y Dick, A. (2016). Análisis de distintas variables productivas y reproductivas, en relación con la edad al parto en vaquillonas Holando argentino/Holstein) (en línea). 1-62. Consultado 10 nov. 2018. Recuperado de http://www.ridaa.unicen.edu.ar/xmlui/ handle/123456789/751.

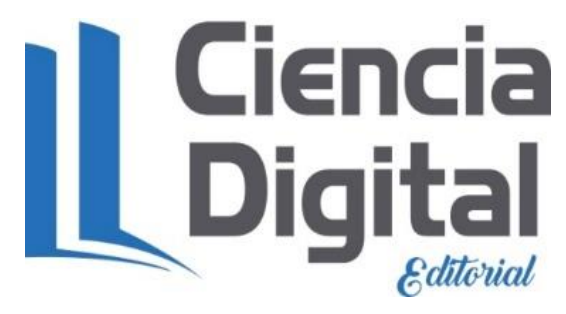




\section{PARA CITAR EL ARTÍCULO INDEXADO.}

Reyes Silva, F. D., Chávez Cossío, J., Condo Plaza, L. A., \& Marini, P. R. (2020). Asociación entre producción de leche y parámetros reproductivos en biotipos Holstein con diferente potencial productivo. Ciencia Digital, 4(3), 6-23.

\section{https://doi.org/10.33262/cienciadigital.v4i3.1273}

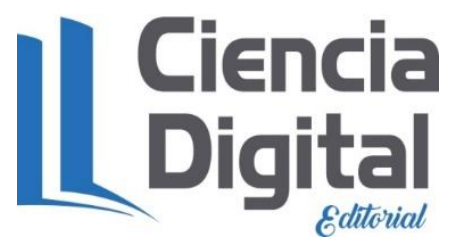

El artículo que se publica es de exclusiva responsabilidad de los autores y no necesariamente reflejan el pensamiento de la Revista Ciencia Digital.

El artículo queda en propiedad de la revista y, por tanto, su publicación parcial y/o total en otro medio tiene que ser autorizado por el director de la Revista Ciencia Digital.
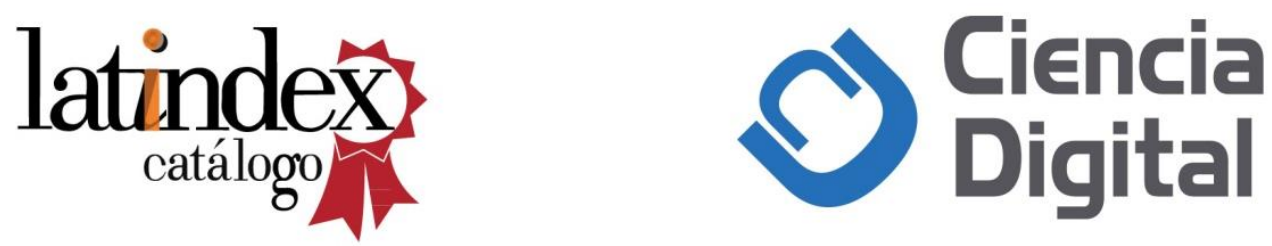